GRAPHICAL ABSTRACT

Synthesis and characterization of novel second-order NLO-chromophores bearing pyrrole as an electron donor group

M. Cidália R. Castro, ${ }^{1}$ M. Belsley,${ }^{2}$ A. Maurício C. Fonseca, ${ }^{1}$ and M. Manuela M. Raposo ${ }^{1 *}$

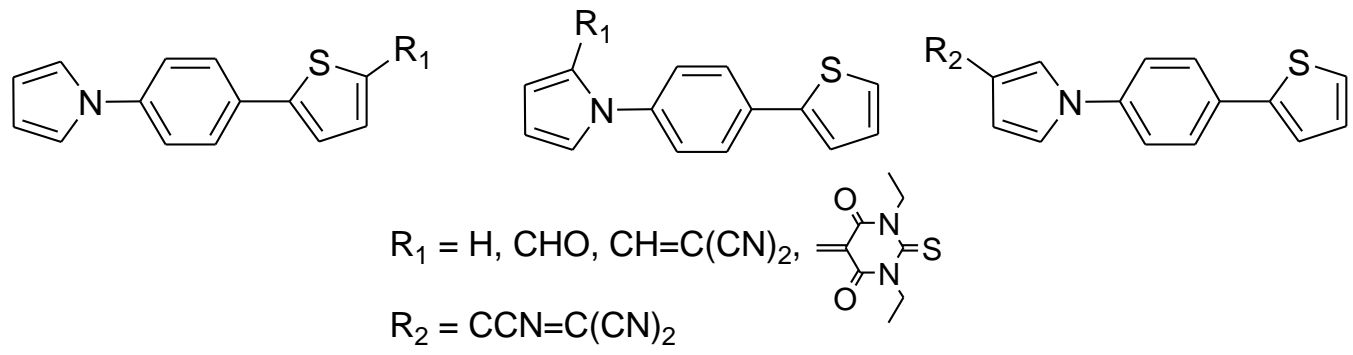




\title{
Synthesis and characterization of novel second-order NLO-chromophores bearing pyrrole as an electron donor group
}

\author{
M. Cidália R. Castro, ${ }^{1}$ M. Belsley, ${ }^{2}$ A. Maurício C. Fonseca, ${ }^{1}$ and M. Manuela M. Raposo ${ }^{1 *}$ \\ ${ }^{1}$ Center of Chemistry, University of Minho, Campus of Gualtar, 4710-057 Braga, Portugal \\ ${ }^{2}$ Center of Physics, University of Minho, Campus de Gualtar, 4710-057 Braga, Portugal
}
${ }^{*}$ Corresponding author Tel: + 351253 604381; Fax: + 351253604382
email:mfox@quimica.uminho.pt

\begin{abstract}
Two series of novel push-pull 1-(4-(thiophen-2-yl)phenyl)-1H-pyrroles 3-5 were designed to explore the consequence of using different electron accepting moieties linked to the thiophene at the arylthiophene bridge or to the pyrrole heterocycle which plays the role of donor group. Compound 2 showed a different reactivity behavior in the presence of the Vilsmeier reagent or with tetracyanoethylene (TCNE) giving compounds $\mathbf{4 a}$ and $\mathbf{4 b}$ functionalized respectively at the 2 or on the 3-position of the pyrrole heterocycle. Their optical (linear and first hyperpolarizability), electrochemical and thermal properties have been examined. Hyper-Rayleigh scattering (HRS) in dioxane solutions using a fundamental wavelength of $1064 \mathrm{~nm}$ was employed to evaluate their second-order nonlinear optical properties. Of these systems, thiobarbituric acid derivative $\mathbf{5 b}$ functionalized in the thiophene ring exhibits the largest first hyperpolarizability $\left(\beta=2480 \times 10^{-30}\right.$ esu, $\mathrm{T}$ convention) compared to the corresponding compound $\mathbf{4} \mathbf{c}$ substituted on the pyrrole heterocycle $(\beta=290$ $\times 10^{-30}$ esu, T convention). Good to excellent thermal stabilities were also obtained for pushpull compounds 4-5 $\left(270-288^{\circ} \mathrm{C}\right)$. This multidisciplinary study shows that modulation of the optical and electronic properties can be achieved by introduction of the acceptor groups in the thiophene of the arylthiophene bridge. The measured molecular first hyperpolarizabilities and the observed electrochemical behavior are quite sensitive to the position of acceptor group on the heterocyclic system (on the thiophene or on the pyrrole ring) as well as the strength of the acceptor moieties. Moreover, the combination of their good nonlinearity and high thermal stability make them good candidates for second order nonlinear optical applications.
\end{abstract}


Keywords: Push-pull heterocyclic systems, Pyrrole, Thiophene, Reactivity studies, Auxiliary donor heterocycle, First hyperpolarizability $(\beta)$, Hyper-Rayleigh scattering (HRS), Redox properties, Thermal stability.

\section{Introduction}

Over the last three decades there has been an intense research effort aimed at improving the nonlinear optical response of push-pull type organic chromophores, motivated by their strong potential to make fundamental improvements in organic modern communication technology, e.g. ultrafast image-processing, optical data processing, transmission, and storage.

Several studies have demonstrated that organic materials have ultrafast response times, low dielectric constants, are easier to tailor or process, and possess stronger NLO responses when compared to inorganic compounds. These advantages are in large part due to their optical properties derived from the high electronic polarisation of the $\pi$-electrons of the molecules instead of the distortions of the atoms in the crystal lattice, which is a slower process. The ease of synthesis and functionalization of organic compounds allows easy optimization of their structural characteristics which is necessary in order to maximize the NLO properties.

One of the major challenges in the design and optimization of the second-order polarizability of organic NLO materials consists in finding substituents with an optimal combination of their donor/ or acceptor strength for a given parent chromophore. ${ }^{1}$

A combination of synthetic innovations ${ }^{2}$ reinforced by theoretical chemical calculations ${ }^{3}$ and confirmed by structural and optical characterizations has shown that the usage of easily delocalized five-membered heteroaromatic rings (usually thiophene, furan, thiazole and imidazole) instead of benzene ring results in an enhanced molecular nonlinear response as quantified through the first molecular hyperpolarizability $\beta$.

Although a large variety of donor, acceptor and spacer groups have been used for the design of NLO chromophores, the use of the pyrrole heterocycle as conjugated bridge and/or as a strong donor moiety has rarely appeared in the NLO literature before $2005^{3 \mathrm{a}-\mathrm{c}, 4}$ probably due to the difficulty of their synthesis. Even rarer are examples of donor-acceptor pyrrole derivatives specifically designed for second-order NLO applications ${ }^{3 a-b, 4 a, 4 c}$ 
Initial work developed in our research group, concerning push-pull functionalized thienylpyrroles, ${ }^{5}$ paved the way for several authors to synthesize and evaluate the first hyperpolarizability $\beta$ for several chromophores bearing pyrrole as $\pi$-bridge or as auxiliary donating group. ${ }^{6}$

Recently, in continuation of our work, we have designed, synthesized and characterized, several series of donor-acceptor substituted 1-alkyl(aryl)-2-thienylpyrroles as donor moieties and/ $\pi$-bridge functionalized with different acceptor groups (benzothiazolyl, benzimidazolyl, aryldiazene and thiazolyldiazene). Evaluation of the electrochemical and optical (linear and nonlinear) properties of these novel donor-acceptor systems revealed that they could be used as potential candidates for second-order NLO and photochromic applications. ${ }^{7}$ Furthermore, our experimental and theoretical results concerning the auxiliary donor/acceptor effect of electron rich and electron deficient heterocycles on push-pull thienylpyrrole $\pi$-conjugated systems have shown that the position of the acceptor groups such as dicyanovinyl or electrondeficient heterocycles, e.g. (benzo)thiazole or benzimidazole on the thienylpyrrolyl system can have a clear influence on the electronic and optical properties of theses heterocyclic chromophores.

We were therefore motivated to extend these studies and explore the potential of two new series of push-pull 1-(4-(thiophen-2-yl)phenyl)-1H-pyrroles 3-5 bearing pyrrole as donor group and dicyanovinyl, tricyanovinyl and thiobarbituric acid as acceptor moieties linked to the arylthiophene spacer or to the pyrrole ring.

The aim of this work is to demonstrate that combined tuning of optical and electrochemical properties of donor-acceptor thiophen-2-yl-phenyl-pyrroles $\mathbf{3 - 5}$ can be achieved by functionalization of these systems with acceptor groups linked to the pyrrole ring (4) or to arylthiophene bridge (3 and 5). Consequently, two series of structurally related chromophores have been designed and the influence of the different position of the acceptor groups on 1-(4-(thiophen-2-yl)phenyl)-1H-pyrroles 4-5 was studied by combined experimental studies of the electronic, linear and nonlinear optical properties of these heterocyclic systems.

Despite the large number of donor-acceptor heterocyclic systems showing NLO properties reported in the literature, the present concept of combining the donor properties of pyrrole heterocycle linked to an arylthiophene bridge functionalized with strong acceptor groups has not, to the best of our knowledge, been previously communicated in the literature. 


\section{Results and discussion}

\subsection{Synthesis}

During the past years we have investigated the reactivity of thienylpyrrole systems. Electrophilic substitution reactions of thienylpyrroles were found to be very selective. The reactivity of these systems has been demonstrated with the use of electrophilic reactions (Vilsmeier formylation, tricyanovinylation, azo coupling) producing derivatives with the electrophile substituted primarily on the pyrrole ring. $5,7 \mathrm{~d}-\mathrm{e}, 8$

In order to prepare two series of 1-(4-(thiophen-2-yl)phenyl)- $1 H$-pyrroles $\mathbf{2 - 5}$ functionalized selectively on the thiophene or on the pyrrole heterocycles different synthetic methodologies were applied (Schemes 1-2). Having in mind our earlier results ${ }^{5 a-b, 8}$ we decided to study the reactivity of the 1-(4-(thiophen-2-yl)phenyl)- $1 H$-pyrrole 2 through electrophilic substitution aiming for the preparation of pyrrole derivatives functionalized selectively on the pyrrole heterocycle. In first place, the 4-bromophenylpyrrole precursor 1 (Ref. 9) was prepared through Paal-Knorr reaction from 2,5-dimethoxy-tetrahydrofurane and 4bromoaniline in high yield (93\%). Suzuki cross-coupling reactions of 1 with thiophen-2-yl boronic acid or 5-formylthiophen-2-yl boronic acid gave respectively compounds $\mathbf{2}$ and $\mathbf{3}$ in 32 and $61 \%$ yields. Compound 2 was used as precursor for the reactivity studies with several electrophiles. Therefore, Vilsmeier formylation of compound 2, with $\mathrm{DMF} / \mathrm{POCl}_{3}$, proceeded selectively in position 2 of the pyrrole ring to form the corresponding formyl-pyrrole $\mathbf{4 a}$ in $59 \%$ yield. On the other hand, tricyanovinylation reaction of 2 with TCNE in DMF using a similar previously reported procedure ${ }^{5 b}$ gave compound $\mathbf{4 b}$ bearing the tetracyanovinyl group on position 3 of the pyrrole ring in $43 \%$ yield. A possible explanation for the different regioselectivity observed for compound $\mathbf{2}$ with TCNE could be probably due to the possible steric influence of the bulky tricyanovinylethylene as well as their pre-coordination to the substrate.

Additionally the thiobarbituric derivative $\mathbf{4 c}$ functionalized on the pyrrole ring was prepared through Knovenagel reaction of aldehyde 4a with 1,3-diethyl-2-thiobarbituric in $39 \%$ yield (Scheme 1$)$.

The structures of pyrroles 4a-c were unambiguously confirmed by their analytical and spectral data. The ${ }^{1} \mathrm{H}$ NMR spectra of compounds $\mathbf{4 a}$ and $\mathbf{4 c}$ exhibit two sets of doublets and an apparent triplet due to protons 4,3 and 5 respectively. In the case of compounds $\mathbf{4 a}$ and $\mathbf{4 c}$ functionalized with the acceptor groups on the 2-position of the pyrrole ring the signal with a higher chemical shift is a doublet of doublets attributed to $3-\mathrm{H}$ with coupling constants in the 
range of 3.3-3.6 Hz and 1.2-1.5 Hz. Protons 4 in compounds $\mathbf{4 a}$ and $\mathbf{4 c}$ appear also as doublet of doublets with coupling constants in the range of 3.3-3.6 Hz and 2.7-2.8 Hz. On the other hand, for compound $\mathbf{4 b}$ the signal with a higher chemical shift appears as an apparent triplet with a coupling constant of $1.5 \mathrm{~Hz}$ which was attributed to $2-\mathrm{H}$.

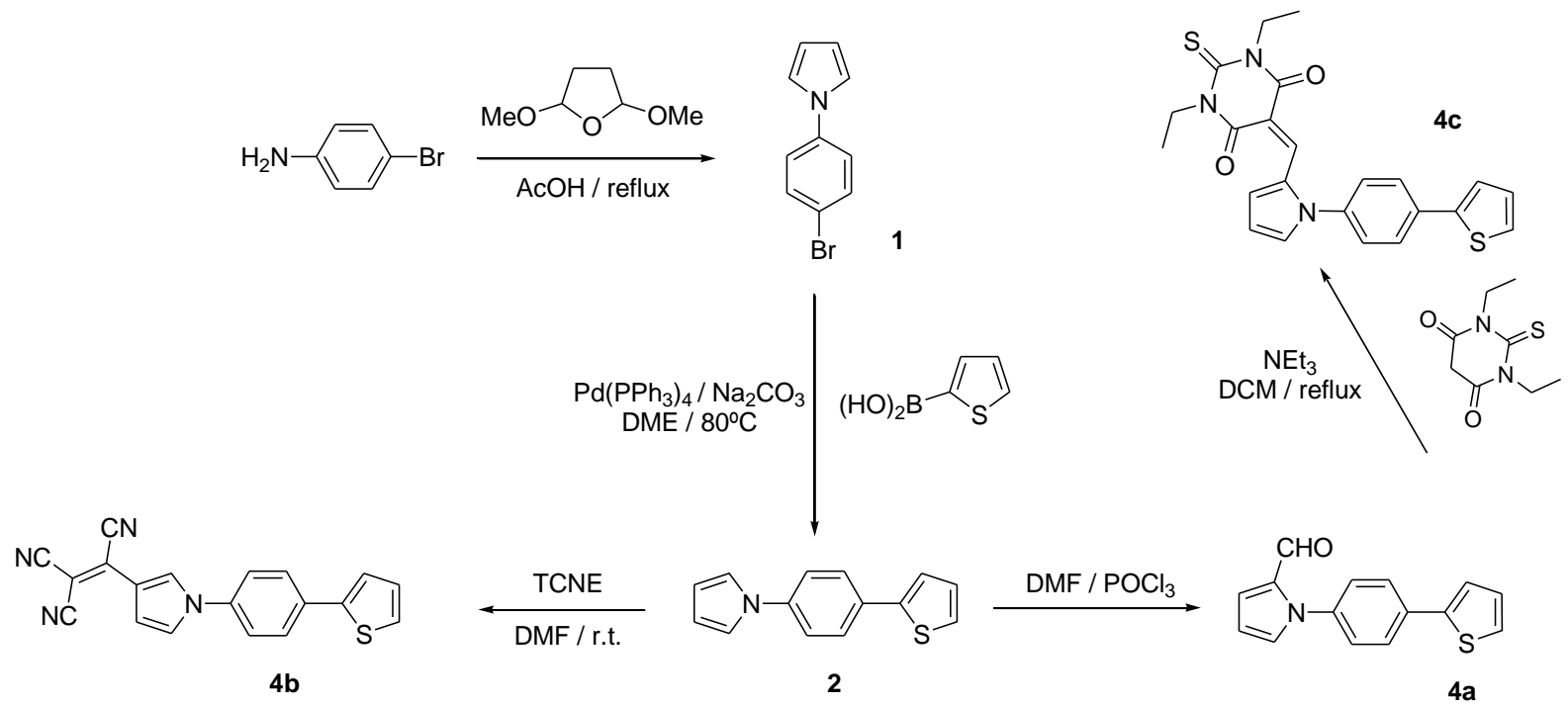

Scheme 1. Synthesis of pyrroles 2 and $4 \mathbf{a}-\mathbf{c}$.

Knovenagel condensation of precursor 3 with malononitrile and 1,3-diethyl-2thiobarbituric gave compounds 5a-b selectively functionalized with the acceptor groups on the thiophene ring in 43 and 65\% yields respectively (Scheme 2).
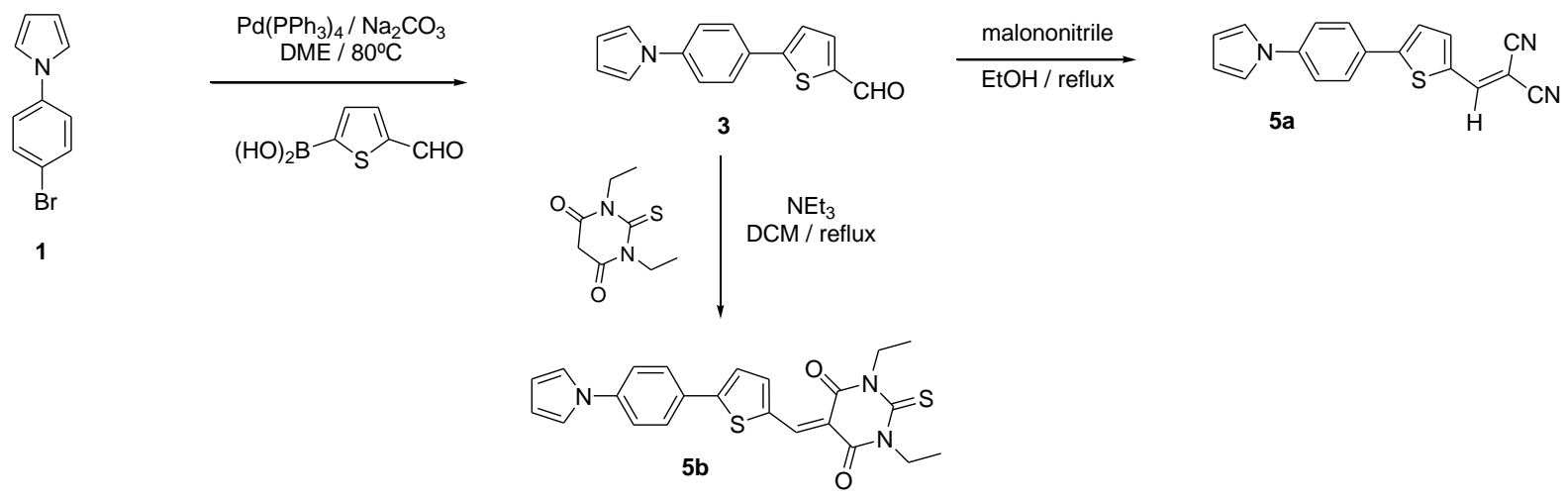

Scheme 2. Synthesis of 1-(4-(thiophen-2-yl)phenyl)-1H-pyrroles 3 and $\mathbf{5 a - b .}$ 
Derivatives $\mathbf{2}$ and $\mathbf{5}$ in which the pyrrole ring is functionalized only in position 1 showed two ${ }^{1} \mathrm{H}$ NMR signals at about 6.38-6.41 and 7.12-7.17 ppm. Both signals appear as multiplets. These signals were attributed respectively, to protons 3 and 4 and 2 and 5 in the pyrrole moiety. In all of the ${ }^{1} \mathrm{H}$ NMR spectra of derivatives $\mathbf{3}$ and $\mathbf{5 a} \mathbf{a}-\mathbf{b}$ two doublets at about 7.42-7.56 and 7.76-7.87 ppm with coupling constants of about 3.9-4.2 Hz were detected. These signals were attributed respectively, to the 4 and $3-\mathrm{H}$ protons of the thiophene moiety.

\subsection{Electronic structure analysis}

The structures and charge transfer transitions of the pyrrole derivatives were first analyzed by ${ }^{1} \mathrm{H}$ NMR spectroscopy and cyclic voltammetry.

The ${ }^{1} \mathrm{H}$ NMR chemical shifts reflect a charge separation in the ground state, consequently the analysis of these data in donor-acceptor compounds such as pyrroles 4-5 bearing dicyanovinyl, tricyanovinyl and thiobarbituric acid moieties also confirms their pushpull character with a significant intramolecular charge transfer (ICT) from the donor pyrrole heterocycle to the acceptor groups and a high polarizability of the whole donor-acceptor derivatives. This interpretation is supported by the observation that the chemical shifts of the protons in compounds 5a-b bearing stronger acceptor groups on the arylthiophene spacer, exhibit signals that are downfield relative to the unsubstituted derivative $\mathbf{2}$ indicating CT from the donor to the acceptor group. On the other hand, stronger acceptor groups substituted on position 2 or 3 of the pyrrole ring on series of compounds 4 also lead to upfield signals for all protons thus again demonstrating the ease of electron communication within the whole heterocyclic system.

At this stage, a comparison can also be made between the ${ }^{1} \mathrm{H}$ NMR data of the new pyrrole 5a with 2-dicyanovinyl-5-(4-pyrrolidinophenyl)thiophene $\mathbf{6},{ }^{10}$ recently reported by us (Table 1). The electronic nature of the donor group, $N, N$-dialkylamino for 6 or heteroaromatic for $\mathbf{5 a}$ had a clear influence on the ${ }^{1} \mathrm{H}$ NMR data of these compounds. Compound 6 bearing a pyrrolidino moiety as donor group exhibits signals that are shifted upfield relative to the corresponding pyrrole derivative 5a indicating the weaker donor ability of the pyrrole heterocycle when compared to a $N, N$-dialkylamino group. The electronic data obtained can be explained by realizing that the pyrrole electron pair is involved in the aromatic system and, thus, not available for delocalization to the acceptor dicyanovinyl group. 
Table 1. Chemical shifts of protons of the arylthiophene derivatives $5 \mathbf{a}$ and $\mathbf{6}^{10}$ in deuterated chloroform at $400 \mathrm{MHz}$, with chemical shift values in ppm.

\begin{tabular}{cccccc}
\hline Comp. & 4-H & $3-\mathrm{H}$ & $3^{\prime}-\mathrm{H}+5^{\prime}-\mathrm{H}^{\prime}$ & $2^{\prime}-\mathrm{H}+6^{\prime}-\mathrm{H}$ \\
\hline $\mathbf{5 a}$ & & & & 7.75 \\
& & & & \\
\end{tabular}

We used cyclic voltammetry to investigate the redox behavior of compounds $\mathbf{2 - 5}$ and obtain their HOMO and lowest occupied molecular orbital (LUMO) energy levels. The redox properties of compounds were measured using $0.1 \mathrm{~mol} \mathrm{dm}^{-3} \mathrm{DMF}^{\mathrm{T}} \mathrm{TBABF}_{4}$ solutions (Table 2). Compounds 2-5 show an irreversible oxidation process associated with the oxidation of the pyrrole group. The oxidation potentials are influenced by the acceptor group substituted on the pyrrole or on the thiophene ring. Therefore, derivatives 3-5 functionalized with strong acceptor groups exhibit an anodic shift compared to the unsubstituted precursor 2. For example, in their reduction traces the cyclic voltammetry of compound $\mathbf{2}$ exhibit two quasi reversible one-electron reduction processes at $-2,23$ e $-2,55 \mathrm{~V}$. On the other hand compound 5a showed reduction potentials at -1.40 and -2.00 V. Derivatives bearing tricyanovinyl (4b), dicyanovinyl (5a) or thiobarbituric acid group (5b) have a different electrochemical behavior. As an example, Figure 1 shows the cyclic voltammetry waves recorded for compounds $\mathbf{4 b}$ and $\mathbf{5 a}$. 


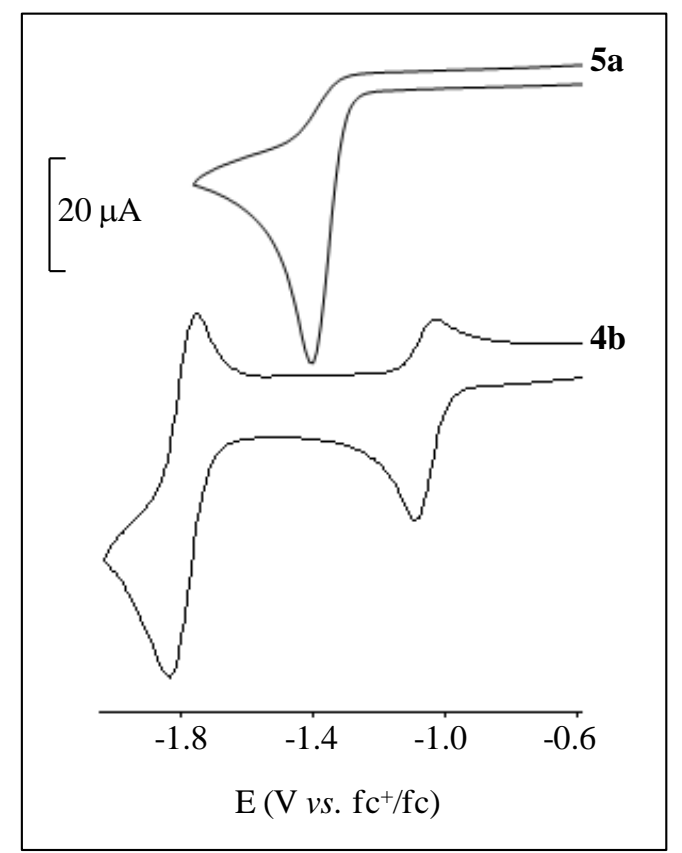

Figure 1. Cyclic voltammograms of compounds $\mathbf{4 b}$ and $\mathbf{5 a}\left(1.0 \times 10^{-3} \mathrm{~mol} \mathrm{dm}^{-3}\right)$ in DMF, 0.1 mol dm${ }^{-3}\left[\mathrm{NBu}_{4}\right]\left[\mathrm{BF}_{4}\right]$ at a vitreous carbon electrode, scan rate $0.1 \mathrm{~V} \mathrm{~s}^{-1}$.

The electrochemical response of the tricyanovinyl compound $\mathbf{4 b}$ consists of stable cathodic processes. The first reduction process near $-1.10 \mathrm{~V}$ is attributed to the tricyanovinyl group due to its strongest electron withdrawing nature. The first sight of the reduction at -1.10 $\mathrm{V}$ can be related to the to the geminal terminal $(\mathrm{CN})_{2}$ groups, whereas the second reduction apparently involves mainly the cross-conjugated $\mathrm{CN}$ group. ${ }^{11}$

For compounds $\mathbf{5 a - b}$, we observe that the first reduction process is irreversible (Figure 1). In these compounds, after the reduction, negative charges in the anionic species are mainly concentrated in the vicinity of the electron withdrawing moieties. For example, in the vinyl $\mathrm{C}(\mathrm{H})$-atom linked the dicyano group, for $\mathbf{5 a}$, or to other acceptor groups such as in compound 5b. Therefore those anion radicals might react between them forming dimmer molecules by generation of new $\mathrm{C}-\mathrm{C}$ bonds. Thus the difference in the reduction behavior for these vinylic derivatives could be attributed to the presence of a quite labile hydrogen atom. ${ }^{5 c, 11-12}$

Comparison of compound $\mathbf{4 c}$ and $\mathbf{5 b}$ bearing a thiobarbituric acid moiety on the pyrrole or on the thiophene moiety, respectively showed that the functionalization of the thiophene ring by the acceptor group results in a larger shift to less reduction potentials (e.g. ${ }^{1} \mathrm{E}_{\mathrm{pc}}=-1.29 \mathrm{~V}$ for $\mathbf{4 c}$ and ${ }^{1} \mathrm{E}_{\mathrm{pc}}=-1.24 \mathrm{~V}$ for $\left.\mathbf{5 b}\right)$. 
At this moment another comparison can also be made between dicyanovinyl derivatives $5 \mathbf{a}$ and $\mathbf{6} .{ }^{10}$ The substitution of a pyrrolidino donor group (6) by the pyrrole ring (5a) results in a decrease of the reduction potentials (e.g. ${ }^{1} \mathrm{E}_{\mathrm{pc}}=-1.40 \mathrm{~V}$ for $\mathbf{5 a}$ and ${ }^{1} \mathrm{E}_{\mathrm{pc}}=-$ $1.50 \mathrm{~V}$ for 6 ) that could be due to the stronger electron-donating ability of pyrrolidino group compared to the pyrrole heterocycle. These results are in agreement with the previous ${ }^{1} \mathrm{H}$ NMR analysis that showed increased electron densities for compound $\mathbf{6}$ compared to $\mathbf{5 a}$.

The HOMO and LUMO energies of all compounds were calculated according to the energy level of the ferrocene reference ( $4.8 \mathrm{eV}$ below vacuum level) ${ }^{13-14}$ Accordingly, the HOMO energy levels of 2-5 were between $-5.68 \mathrm{eV}$ and $-5.78 \mathrm{eV}$, showing the variations resulting from the presence of different electron-withdrawing substitutents on the pyrrole or on the thiophene heterocycles. The LUMO energy levels of 2-5 were all located between 2.57 and $3.70 \mathrm{eV}$ thus, the energy of this orbital is strongly influenced by the presence of electron withdrawing groups in the system. In addition, the electrochemical bandgaps, estimated from the difference between the onset potentials for oxidation and reduction, were in the range $2.03-3.13 \mathrm{eV}$. The efficient donor-acceptor conjugation leads to a lowering of the HOMO and the LUMO levels in $\mathbf{3}$ and $\mathbf{5 a - b}$, revealing a more efficient coupling between the 1-(4-(thiophen-2-yl)phenyl)-1H-pyrrole system and the formyl, dicyanovinyl and thiobarbituric acceptor groups.

The analysis of the electrochemical data for compounds 2-5 showed that the functionalization of compound $\mathbf{2}$ with acceptor groups leads to two series of push-pull chromophores $\mathbf{4}$ and $\mathbf{5}$ and in both cases the electronic acceptor strength has a strong influence on the electronic delocalization of the $\pi$-conjugated systems. Moreover, as expected the stronger acceptor substituents leads to smaller band gaps values. 
Table 2. Electrochemical data for compounds 2-5.

\begin{tabular}{|c|c|c|c|c|c|c|c|c|c|c|}
\hline \multirow[b]{2}{*}{ Comp. } & \multicolumn{6}{|c|}{ Reduction $^{\text {a }}$} & \multirow{2}{*}{$\begin{array}{c}\text { Oxidation }^{\mathbf{a}} \\
\mathbf{E}_{\mathbf{p a}} \\
(\mathbf{V})\end{array}$} & \multirow[b]{2}{*}{$\begin{array}{c}\text { HOMO }^{c} \\
(\mathrm{eV})\end{array}$} & \multirow[b]{2}{*}{$\begin{array}{c}\text { LUMO }^{\mathbf{c}} \\
(\mathrm{eV})\end{array}$} & \multirow[b]{2}{*}{$\begin{array}{c}\text { Band gap }^{\mathrm{d}} \\
(\mathrm{eV})\end{array}$} \\
\hline & $\begin{array}{l}{ }^{-1} \mathbf{E}_{\mathbf{p c}} \\
(\mathbf{V})\end{array}$ & $\begin{array}{c}\Delta \mathbf{E}^{\mathrm{b}} \\
(\mathrm{mV})\end{array}$ & $\begin{array}{l}-^{2} \mathbf{E}_{\mathbf{p c}} \\
(\mathbf{V})\end{array}$ & $\begin{array}{c}\Delta \mathbf{E}^{\mathrm{b}} \\
(\mathrm{mV})\end{array}$ & $\begin{array}{c}-{ }^{3} \mathbf{E}_{\mathbf{p c}} \\
(\mathbf{V})\end{array}$ & $\begin{array}{c}\Delta E^{b} \\
(m V)\end{array}$ & & & & \\
\hline 2 & 2.23 & 180 & 2.55 & 220 & - & & 0.88 & -5.68 & -2.57 & 3.13 \\
\hline 3 & 2.10 & 130 & 2.60 & - & - & - & 0.91 & -5.71 & -2.70 & 3.01 \\
\hline $4 a$ & 2.15 & 63 & 2.56 & & & & 0.91 & -5.71 & -2.65 & 3.06 \\
\hline $4 b$ & 1.10 & 60 & 1.84 & 70 & 2.90 & 190 & 0.93 & -5.73 & -3.70 & 2.03 \\
\hline $4 c$ & 1.29 & 72 & 2.21 & - & - & - & 0.95 & -5.75 & -3.51 & 2.24 \\
\hline $5 a$ & 1.40 & - & 2.00 & - & - & - & 0.92 & -5.72 & -3.40 & 2.32 \\
\hline $5 b$ & 1.24 & - & 1.94 & 70 & - & - & 0.98 & -5.78 & -3.56 & 2.22 \\
\hline
\end{tabular}

${ }^{\text {a }}$ Measurements made in dry DMF containing $1.0 \mathrm{mM}$ in each compounds and $0.10 \mathrm{M}\left[\mathrm{NBu}_{4}\right]\left[\mathrm{BF}_{4}\right]$ as base electrolyte at a carbon working electrode with a scan rate of $0.1 \mathrm{~V} \mathrm{~s}^{-1}$. All E values are quoted in volts $v s$ the ferrocenium/ferrocene -couple. $E_{\mathrm{pc}}$ and $E_{\mathrm{pa}}$ correspond to the cathodic and anodic peak potentials, respectively.

${ }^{\mathrm{b}} \Delta \mathrm{E}=\left|\mathrm{E}_{\mathrm{red}}-\mathrm{E}_{\mathrm{ox}}\right|$.

${ }^{\mathrm{c}} \mathrm{E}_{\mathrm{HOMO}}$ and $\mathrm{E}_{\mathrm{Lumo}}$ were calculated according to the energy level of the ferrocene reference $4.80 \mathrm{eV}$ below vacuum level. $\mathrm{E}_{\mathrm{HOMO}}=-\left(4.80+\mathrm{E}_{\mathrm{pa}}\right)$ $(\mathrm{eV})$ and $\mathrm{E}_{\mathrm{LUMO}}=-\left({ }^{1} \mathrm{E}_{\mathrm{pc}}+4.80\right)(\mathrm{eV})$.

${ }^{\mathrm{d}}$ Band gap calculated form the difference between $\mathrm{E}_{\mathrm{LUMO}}$ and $\mathrm{E}_{\mathrm{HOMO}}{ }^{10}$ 


\subsection{Optical properties}

Pyrrole derivatives 2-5 showed good solubility in common polar and non-polar organic solvents such as dioxane, diethyl ether, ethanol, DMF and DMSO. The extinction coefficients $(\varepsilon)$ and the wavelength maxima $\lambda_{\max }$ of compounds $\mathbf{2 - 5}$ in several solvents, are summarized in Table 3 and were compared with the $\pi^{*}$ values for each solvent, as determined by Kamlet and Taft. ${ }^{15}$ All chromophores exhibit broad and intense CT absorptions in the visible region from $306 \mathrm{~nm}$ to $465 \mathrm{~nm}$ in dioxane solutions. The position of this band was strongly influenced by the electronic nature of the acceptor moiety and also by the position of substitution of this group in the $\pi$-bridge (on the pyrrole or on the thiophene heterocycle). Therefore, the absorption maxima $\left(\lambda_{\max }\right)$ of pyrrole-based chromophores $\mathbf{4 a - c}$, in dioxane are located at the range of 308 to $433 \mathrm{~nm}$, on the other hand compounds $\mathbf{3}$ and $\mathbf{5 a - b}$ bearing the acceptor group on the thiophene moiety exhibit absorption maxima $\left(\lambda_{\max }\right)$ located at the range of 349 to $465 \mathrm{~nm}$ probably due to more extensive electron delocalization. As observed earlier for other pyrrole push-pull systems, a bathochromic shift in the UV-Vis. spectra is observed when stronger acceptor groups are linked to the heterocyclic system. ${ }^{5,7 \mathrm{a}-\mathrm{b}, 7 \mathrm{~d}-\mathrm{e}}$ For example, the substitution of a hydrogen for a thiobarbituric acid moiety leads to a red shift of $127 \mathrm{~nm}$ from $306 \mathrm{~nm}$ (2) to $433 \mathrm{~nm}(\mathbf{4 c})$, furthermore a larger red-shifted $\lambda_{\max }(159 \mathrm{~nm})$ was obtained for derivative $\mathbf{5 b}$ bearing the acceptor group on the thiophene ring when compared with the same compound 2.

Within the two series of compounds $\mathbf{4 a}, \mathbf{4} \mathbf{c}$ and $\mathbf{3}$ and $\mathbf{5 a - b}$ the CT bands moves to lower energies as the electron accepting ability of the acceptor moiety increases, in the order $\mathrm{CHO}<$ dicyanovinyl $<$ thiobarbituric acid (Figure 2). These results agree with the band gap calculations based on the redox properties (Table 2), which show decreased band gaps for derivatives $\mathbf{4 b}, \mathbf{4} \mathbf{c}$ and $\mathbf{5 a}-\mathbf{b}$ functionalized with strong electron acceptor groups.

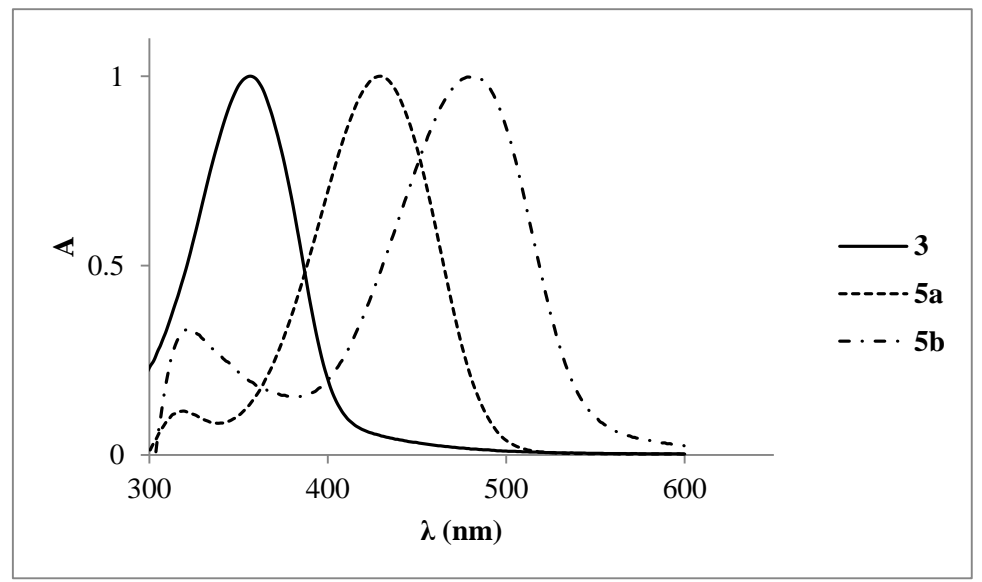

Figure 2. Comparative absorption spectra of $\mathbf{3}$ and $\mathbf{5 a - b}$ in dioxane at room temperature. 
Compounds 2-5 exhibit positive solvatochromism $\left(\Delta v_{\max }=529-1019 \mathrm{~cm}^{-1}\right)$ with respect to their CT absorption band, that is, the position of the absorption maximum shifts to longer wavelengths as the polarity of the solvent increases due to a greater stabilization of the excited state relative to the ground state with increasing polarity of the solvent (Table 3 ).

Table 3. Solvatochromic data $\left[\lambda_{\max }(\mathrm{nm})\right.$ and $\Delta \mathrm{v}_{\max }\left(\mathrm{cm}^{-1}\right)$ of the charge-transfer band $]$ for pyrroles 2-5 in 5 solvents with $\pi^{*}$ values by Kamlet and Taft. ${ }^{15}$

\begin{tabular}{|c|c|c|c|c|c|c|}
\hline Comp. & $\begin{array}{c}\text { Diethyl ether } \\
(0.54) \\
\lambda_{\max }(\mathrm{nm})\end{array}$ & $\begin{array}{c}\text { 1,4-Dioxane } \\
(0.55) \\
\lambda_{\max }(\mathrm{nm})\end{array}$ & $\begin{array}{c}\text { Chloroform } \\
(0.76) \\
\lambda_{\max }(\mathrm{nm})\end{array}$ & $\begin{array}{c}\text { DMSO } \\
(1.00) \\
\lambda_{\max }(\mathrm{nm})\end{array}$ & $\begin{array}{l}\Delta v_{\max }^{a} \\
\left(\mathrm{~cm}^{-1}\right)\end{array}$ & $\begin{array}{c}\varepsilon \\
\text { (Dioxane) } \\
\left(\mathrm{M}^{-1} \mathrm{~cm}^{-1}\right)\end{array}$ \\
\hline 2 & 305 & 306 & 307 & 310 & 529 & 39,720 \\
\hline 3 & 345 & 349 & 350 & 357 & 974 & 32,740 \\
\hline $4 a$ & 306 & 308 & 309 & 313 & 731 & 28,420 \\
\hline $4 b$ & 400 & 403 & 413 & 417 & 1019 & 31,990 \\
\hline $4 c$ & 430 & 433 & 441 & 445 & 784 & 45,790 \\
\hline $5 \mathbf{a}$ & 415 & 416 & 425 & 430 & 841 & 39,180 \\
\hline $5 b$ & 461 & 465 & 478 & 479 & 815 & 45,790 \\
\hline
\end{tabular}

${ }^{\mathrm{a}} \Delta v_{\max }=v_{\max }\left(\right.$ diethyl ether $-v_{\max }(\mathrm{DMSO}) / \mathrm{cm}^{-1}$ 
The molecular first hyperpolarizabilities $\beta$ of compounds 2-5 were measured by hyper-Rayleigh scattering (HRS) method ${ }^{16}$ at a fundamental wavelength of $1064 \mathrm{~nm}$ of a laser beam. Dioxane was used as the solvent, and the $\beta$ values were measured against a reference solution of $p$-nitroaniline $(p \mathrm{NA})^{17}$ in order to obtain quantitative values, while care was taken to properly account for possible fluorescence of the dyes (see experimental section for more details). The static hyperpolarisability $\beta_{0}$ values $^{18}$ were calculated using a very simple twolevel model neglecting damping. They are therefore only indicative and should be treated with caution (Table 4).

Table 4. UV-vis absorptions, $\beta$ and $\beta_{0}$ values and $\mathrm{T}_{d}$ data for pyrrole derivatives $\mathbf{2 - 5}$ and thienylpyrrole $7 .^{5 \mathrm{c}}$

\begin{tabular}{cccccc}
\hline Compounds & $\begin{array}{c}\text { Yield } \\
(\%)\end{array}$ & $\begin{array}{c}\lambda_{\max } \\
(\mathrm{nm})\end{array}$ & $\begin{array}{c}\beta^{\mathrm{b}}(\mathrm{conv}) \\
\left(10^{-30} \mathrm{esu}\right)\end{array}$ & $\begin{array}{c}\beta_{0}{ }^{\mathrm{c}}(\mathrm{conv} \mathrm{T}) \\
\left(10^{-30} \mathrm{esu}\right)\end{array}$ & $\begin{array}{c}\mathrm{T}_{d}{ }^{\mathrm{d}} \\
\left({ }^{\circ} \mathrm{C}\right)\end{array}$ \\
\hline $\mathbf{2}$ & 32 & 309 & $*^{1}$ & $*^{1}$ & 194 \\
$\mathbf{3}$ & 41 & 349 & 66 & 34 & 199 \\
$\mathbf{4 a}$ & 59 & 308 & $* 1$ & $* 1$ & --- \\
$\mathbf{4 b}$ & 43 & 403 & 225 & 82 & 288 \\
$\mathbf{4 c}$ & 39 & 433 & 290 & 82 & --- \\
$\mathbf{5 a}$ & 65 & 416 & 2200 & 725 & 277 \\
$\mathbf{5 b}$ & 65 & 465 & 2480 & 474 & 270 \\
$\mathbf{6}^{10}$ & --- & 503 & $* 2$ & $*^{2}$ & --- \\
$\mathbf{7}^{5 \mathrm{c}}$ & --- & 450 & 860 & 200 & --- \\
$\boldsymbol{p} \boldsymbol{N} \boldsymbol{A}$ & --- & 352 & 40 & 20 & -- \\
\hline
\end{tabular}

${ }^{a}$ Experimental first hyperpolarizabilities $\beta$ and spectroscopic data measured in dioxane solutions.

${ }^{\mathrm{b}}$ All compounds are transparent at the $1064 \mathrm{~nm}$ fundamental wavelength.

${ }^{\mathrm{c}}$ Data corrected for resonance enhancement at $532 \mathrm{~nm}$ using the two-level model with $\beta_{0}=\beta$ $\left[1-\left(\lambda_{\max } / 1064\right)^{2}\right]\left[1-\left(\lambda_{\max } / 532\right)^{2}\right] ;$ damping factors not included $1064 \mathrm{~nm} .^{18}$

${ }^{\mathrm{d}}$ Decomposition temperature $\left(\mathrm{T}_{d}\right)$ measured at a heating rate of $20{ }^{\circ} \mathrm{C} \mathrm{min}{ }^{-1}$ under a nitrogen atmosphere, obtained by thermogravimetric analysis (TGA).

${ }^{*}$ Due to a combination of low signals and fluorescence it was not possible to measure the $\beta$ value.

$*^{2}$ Due to fluorescence it was not possible to measure the $\beta$ value. 
It was not possible to measured the $\beta$ value for compounds $\mathbf{2}$ and $\mathbf{4 a}$ due to a combination of low absolute signals and fluorescence contamination at $532 \mathrm{~nm}$. From Table 4 it is clear that the progression of acceptor substituents from formyl, dicyanovinyl and thiobarbituric acid results in enhanced nonlinearities as anticipated from the acceptor strengths of the substituents. As expected compounds $\mathbf{5 b}$ and $\mathbf{4 c}$ exhibit the highest $\beta$ values.

Moreover $\beta$ values for compounds having the acceptor groups on the thiophene ring are 55-62 times greater than $p \mathrm{NA}$, whereas the respective $\beta_{0}$ are 24-36 times greater. On the other hand compounds 4 functionalized with acceptor moieties on the pyrrole ring exhibit smaller $\beta$ values when compared to the corresponding compounds $\mathbf{5}$. For example, $\mathbf{5 b}$ exhibits a $\beta$ value of $2480 \times 10^{-30}$ esu while for $4 \mathbf{c}$ the $\beta$ value is 8 times smaller $\left(290 \times 10^{-30} \mathrm{esu}\right)$. The results obtained show that the location of the acceptor group on the pyrrole or on the thiophene ring alone can dramatically alter the overall molecular nonlinearity of the system. Pyrrole, being the most electron-rich five-member heteroaromatic ring, counteracts the electron withdrawing effect of the acceptor groups, resulting in a decrease in $\beta$. These findings are in accordance with our recent work related to push-pull thienylpyrroles ${ }^{5 c, 7 a-b}$ where it was concluded that the increase or decrease of the molecular nonlinear activity in these systems depends on the electronic nature of the heterocycles as well as the location of the acceptor groups in these heterocyclic systems.

The thermal stability of chromophores $\mathbf{2 - 5}$ was characterized by thermogravimetric analysis (Figure 3). The samples had moderate to high decomposition temperatures $\left(\mathrm{T}_{d}=199\right.$ - $288{ }^{\circ} \mathrm{C}$ ), measured at a heating rate of $20{ }^{\circ} \mathrm{C} \min ^{-1}$ under a nitrogen atmosphere. Experimental results indicate that good nonlinearity-thermal stability is well balanced for these chromophores, specially for compounds $\mathbf{5 a - b}$ which possess a $\beta$ values at the range of $2200-2480 \times 10^{-30}$ esu and high decomposition temperatures $\left(\mathrm{T}_{d}=270-27{ }^{\circ} \mathrm{C}\right)$.

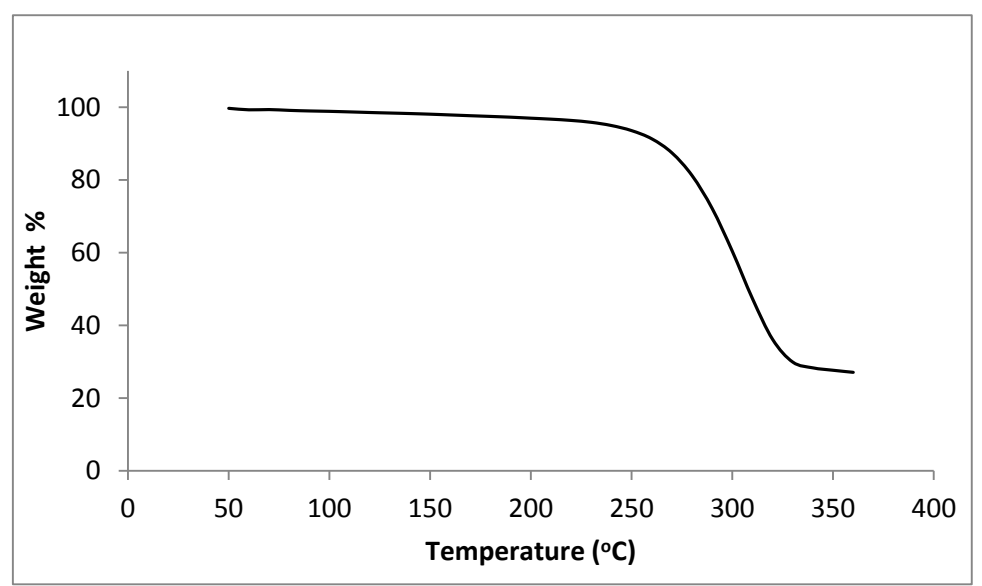


Figure 3. Thermal analysis data for compound 5a through TGA recorded under a nitrogen atmosphere, measured at a heating rate of $20^{\circ} \mathrm{C} \mathrm{min}^{-1}$.

\section{Conclusions}

In conclusion we have developed two new series of push-pull pyrrole NLOheterocyclic systems functionalized with acceptor groups on the pyrrole $(\mathbf{4 a - c})$ or on the thiophene heterocycles ( $\mathbf{3}$ and $\mathbf{5 a}-\mathbf{b})$.

Reactivity studies of compound $\mathbf{2}$ in the presence of different electrophiles (Vilsmeier reagent or with tetracyanoethylene) showed that the strongest and bulky electrophile react in position 3 of the pyrrole heterocycle to produce compound $\mathbf{4 b}$ while the Vilsmeier reagent give rise to the derivative 4 a functionalized on position 2 of the pyrrole ring.

By varying the position of linkage of the acceptor moiety the electrochemical properties of compounds 4-5 as well as the linear and nonlinear optical properties of these push-pull $\pi$-conjugated systems can be readily tuned.

Electrochemical studies and characterization of the optical (linear and nonlinear), and thermal properties for compounds 2-5 indicate that, good nonlinearity-thermal stability is well balanced for chromophores 5a-b, making them good candidates for several optoelectronic applications such as solvatochromic probes and second order nonlinear optical materials. 


\section{Experimental}

\subsection{Materials}

Thiophen-2-yl-boronic acid, 5-formyl-thiophen-2-yl-boronic acid, 4-bromoaniline and 2,5dimethoxytetradihydrofuran used as precursors for the synthesis of pyrroles 1-5 were purchased from Aldrich and Fluka and used as received. TLC analyses were carried out on $0.25 \mathrm{~mm}$ thick precoated silica plates (Merck Fertigplatten Kieselgel $60 \mathrm{~F}_{254}$ ) and spots were visualised under UV light. Chromatography on silica gel was carried out on Merck Kieselgel (230-240 mesh).

\subsection{Synthesis}

Compound 1 was synthesized using the experimental procedure described earlier. ${ }^{9}$

1-(4-Bromophenyl)-1H-pyrrole 1. Pale brown solid (242 mg, 93\%). ${ }^{1} \mathrm{H}$ NMR $\left(\mathrm{CDCl}_{3}\right) \delta 6.36$ 6.38 (m, 2H, 3-H and 4-H), 7.05-7.07 (m, 2H, 2-H and 5-H), 7.28 (d, 2H, J=8.6 Hz 2'-H and 6'-H), 7.55 (d, 2H, J=8.6 Hz, 3'-H and 5'-H).

General procedure for the synthesis of pyrroles $\mathbf{2}$ and $\mathbf{3}$ through Suzuki cross coupling reaction $^{19}$

1-(4-Bromophenyl)-1H-pyrrole 1 (0.90 mmol, $200 \mathrm{mg}$ ) was coupled to thiophen-2-yl-boronic acid or 5-formyl-thiophen-2-yl-boronic acid $(1.12 \mathrm{mmol})$ in a mixture of DME $(10 \mathrm{ml})$, aqueous $2 \mathrm{M} \mathrm{Na}_{2} \mathrm{CO}_{3}(1 \mathrm{ml})$ and $\mathrm{Pd}\left(\mathrm{PPh}_{3}\right)_{4}(3 \mathrm{~mol} \%)$ at $80{ }^{\circ} \mathrm{C}$ under nitrogen. The reaction was monitored by TLC, which determined the reaction time (24-32 h). After cooling, the mixture was extracted with chloroform $(3 \times 20 \mathrm{ml})$ and a saturated solution of $\mathrm{NaCl}$ were added $(20 \mathrm{ml})$ and the phases were separated. The organic phase was washed with water $(3 \times 10 \mathrm{ml})$ and with a solution of $\mathrm{NaOH}(10 \%)(1 \times 10 \mathrm{ml})$. The organic phase obtained was dried $\left(\mathrm{MgSO}_{4}\right)$, filtered, and the solvent removed to give a crude mixture. The crude product was purified through a silica gel chromatography column using mixtures of chloroform and light petroleum of increasing polarity to afford the coupled products $\mathbf{2}$ or $\mathbf{3}$. Recrystallization from light petroleum/ether gave the pure compounds.

1-(4-(Thiophen-2-yl)phenyl)-1H-pyrrole 2. Pale bege solid (65 mg, 32\%). Mp 215-216 ${ }^{\circ} \mathrm{C} .{ }^{1} \mathrm{H}$ $\operatorname{NMR}\left(\mathrm{CDCl}_{3}\right) \delta$ 6.38-6.39 (m, 2H, 3-H and 4-H), $7.11(\mathrm{dd}, 1 \mathrm{H}, J=5.2$ and 3.6 Hz, 4' '-H), 7.12-7.14 (m, 2H, 2- and 5-H), 7.29-7.33 (m, 2H, 3''-H and 5' '-H), 7.42 (d, 2H, J=9.0 Hz, 2'$\mathrm{H}$ and $\left.6^{\prime}-\mathrm{H}\right), 7.68\left(\mathrm{~d}, 2 \mathrm{H}, J=9.0 \mathrm{~Hz}, 3{ }^{\prime}-\mathrm{H}\right.$ and 5'-H). ${ }^{13} \mathrm{C} \mathrm{NMR}\left(\mathrm{CDCl}_{3}\right) \delta 110.6,119.2,120.7$, $123.1,124.9,127.0,128.1,131.9,139.9,143.4 . \lambda_{\max }($ Dioxane $) / \mathrm{nm} 306\left(\varepsilon / \mathrm{dm}^{3} \mathrm{~mol}^{-1} \mathrm{~cm}^{-1}\right.$ 
39,720). IR $\left(\mathrm{CHCl}_{3}\right)$ : v 3139, 1886, 1605, 1538, 1509, 1333, 1252, 1133, 1079, 854, 819, 703

$\mathrm{cm}^{-1}$. MS (ESI) $\mathrm{m} / z(\%)=226\left([\mathrm{M}+\mathrm{H}]^{+}, 100\right), 225$ (64), 209 (38), 203 (37). HMRS: $\mathrm{m} / z$ (ESI) for $\mathrm{C}_{14} \mathrm{H}_{11} \mathrm{NS}$; calcd 226.0685; found: 226.0684. Anal. Calcd for $\mathrm{C}_{14} \mathrm{H}_{11} \mathrm{NS}$ : C, 74.63; $\mathrm{H}$, 4.92; N, 6.22; S, 14.23. Found: C, 74.85; H, 5.30; N, 6.55; S, 14.60.

5-(4-(1H-Pyrrol-1-yl)phenyl)thiophene-2-carbaldehyde 3. Orange solid (210 mg, 61\%). Mp. 205-206 ${ }^{\circ} \mathrm{C} .{ }^{1} \mathrm{H}$ NMR $\left(\mathrm{CDCl}_{3}\right) \delta$ 6.39-6.41 (m, 2H, 3' '-H and 4' '-H), 7.14-7.16 (m, 2H, 2"'and 5' $-\mathrm{H}), 7.42(\mathrm{~d}, 1 \mathrm{H}, J=4.2 \mathrm{~Hz}, 4-\mathrm{H}), 7.47\left(\mathrm{~d}, 2 \mathrm{H}, J=8.9 \mathrm{~Hz}, 3^{\prime}-\mathrm{H}\right.$ and 5'-H) , $7.74(\mathrm{~d}, 2 \mathrm{H}$, $J=8.9 \mathrm{~Hz}, 2^{\prime}-\mathrm{H}$ and 6'-H), 7.76 (d, 1H, $\left.J=4.2 \mathrm{~Hz}, 3-\mathrm{H}\right), 9.91$ (s, 1H, CHO). ${ }^{13} \mathrm{C} \mathrm{NMR}\left(\mathrm{CDCl}_{3}\right)$ $\delta 111.1,119.1,120.6,123.9,127.7,130.2,137.5,141.3,142.4,153.2,182.7 . \lambda_{\max }$ (Dioxane)/nm $349\left(\varepsilon / \mathrm{dm}^{3} \mathrm{~mol}^{-1} \mathrm{~cm}^{-1} 32,740\right)$. IR $\left(\mathrm{CHCl}_{3}\right)$ : v 3442, 3148, 2945, 1648, 1605, 1536, 1480, 1449, 1330, 1233, 1001, 919, 826, 805, $730 \mathrm{~cm}^{-1}$. MS (ESI) $\mathrm{m} / \mathrm{z}(\%)=254$ $\left([\mathrm{M}+\mathrm{H}]^{+}, 100\right)$. HMRS: $m / z$ (ESI) for $\mathrm{C}_{15} \mathrm{H}_{11} \mathrm{NOS}$; calcd 254.0634; found: 254.0630. Anal. Calcd for $\mathrm{C}_{15} \mathrm{H}_{11} \mathrm{NOS}$ : C, 71.12; H, 4.38; N, 5.53; S, 12.66. Found: C, 71.29; H, 4.57; N, 5.85; S, 13.00.

Synthesis of compound $\mathbf{4 a}$

$\mathrm{POCl}_{3}(0.44 \mathrm{mmol})$ was added to DMF $(0.44 \mathrm{mmol})$ at $0{ }^{\circ} \mathrm{C}$ and the mixture was stirred for $15 \mathrm{~min}$. at $0{ }^{\circ} \mathrm{C}$. After this time pyrrole $2(0.44 \mathrm{mmol})$ dissolved in DMF $(2 \mathrm{ml})$ were added dropwise with stirring. The reaction mixture was then heated $4 \mathrm{~h}$ at $60^{\circ} \mathrm{C}$. The solution was then poured slowly into $10 \mathrm{ml}$ saturated sodium acetate aqueous solution and stirred $30 \mathrm{~min}$.. The organic layer was diluted with ether $(25 \mathrm{ml})$, washed with saturated $\mathrm{NaHCO}_{3}$ aqueous solution $(2 \times 25 \mathrm{ml})$, and dried with anhydrous $\mathrm{MgSO}_{4}$. Evaporation of the organic extract under reduced pressure gave the crude aldehyde 4a which was purified through a silica gel chromatography column using mixtures of chloroform and light petroleum of increasing polarity to afford aldehyde 4a. Recrystallization from light petroleum/ether gave the pure compound.

1-(4-(Thiophen-2-yl)phenyl-1H-pyrrole-2-carbaldehyde 4a. Pale bege solid (66 mg, 59\%). Mp 215-216 ${ }^{\circ} \mathrm{C} .{ }^{1} \mathrm{H}$ NMR $\left(\mathrm{CDCl}_{3}\right) \delta 6.44(\mathrm{dd}, 1 \mathrm{H}, J=3.6$ and $2.8 \mathrm{~Hz}, 4-\mathrm{H}), 7.11-7.13(\mathrm{~m}, 2 \mathrm{H}$, 5-H and 4' '-H), 7.19 (dd, 1H, J=3.6 and 1.2 Hz, 3-H), 7.34 (dd, 1H, J= 5.2 and 1.2 Hz, 5' '-H), 7.37-7.39 (m, 3H, 3'-H, 5'-H and 3''-H), 7.70 (d, 2H, J=8.6 Hz, 2'-H and 6'-H), 9.62 (s, 1H, $\mathrm{CHO}) .{ }^{13} \mathrm{C} \mathrm{NMR}\left(\mathrm{CDCl}_{3}\right) \delta 111.0,122.7,123.8,125.5,126.4,128.2,131.1,132.4,134.4$, 137.8, 143.0, 179.0, 192.5. $\lambda_{\max }($ Dioxane $) / \mathrm{nm} 308\left(\varepsilon / \mathrm{dm}^{3} \mathrm{~mol}^{-1} \mathrm{~cm}^{-1} 28,420\right)$. IR $\left(\mathrm{CHCl}_{3}\right): v$ 
3123, 1766, 1673, 1660, 1533, 1523, 1318, 1303, 1280, 1261, 1238, 1210, 1195, 1091, 1036 $\mathrm{cm}^{-1}$. MS (ESI) $\mathrm{m} / \mathrm{z}(\%)=254\left([\mathrm{M}+\mathrm{H}]^{+}, 100\right)$. HMRS: $\mathrm{m} / z(\mathrm{ESI})$ for $\mathrm{C}_{15} \mathrm{H}_{12} \mathrm{NOS}$; calcd 254.0634; found: 254.0632. Anal. Calcd for $\mathrm{C}_{15} \mathrm{H}_{11} \mathrm{NOS}$ : C, 71.12; H, 4.38; N, 5.53; S, 12.66 . Found: C, 71.29; H, 4.57; N, 5.85; S, 12.88 .

Synthesis of compound $\mathbf{4 b}$

A solution of compound $2(0.22 \mathrm{mmol}, 50 \mathrm{mg})$ in DMF $(1.5 \mathrm{ml})$ was cooled at $0^{\circ} \mathrm{C}$ and then tetracyanoethylene $(0.44 \mathrm{mmol}, 57 \mathrm{mg})$ was added slowly. The reaction mixture was stirred at room temperature for about 2 hours. After this time the mixture was poured into ice/water (5 $\mathrm{ml})$ and the organic layer was diluted in chloroform $(10 \mathrm{ml})$, washed with water $(2 \times 20 \mathrm{ml})$, and dried with anhydrous $\mathrm{MgSO}_{4}$. Evaporation of the solvent under reduced pressure gave the crude product, which was recrystallized from chloroform giving the pure product $\mathbf{4 b}$.

1-(1-(4-(Thiophen-2-yl)phenyl)-1H-pyrrol-2-yl)ethene-1,2,2-tricarbonitrile 4b. Dark orange solid (21 mg, 43\%). Mp 257-259 ${ }^{\circ} \mathrm{C} .{ }^{1} \mathrm{H}$ NMR (Acetone-d $\left.{ }_{6}\right) \delta 7.21(\mathrm{dd}, 1 \mathrm{H}, J=5.1$ and $3.9 \mathrm{~Hz}$, 4' '-H), 7.29 (dd,1H, $J=2.7$ and $2.1 \mathrm{~Hz}, 4-\mathrm{H}), 7.58$ (dd, $1 \mathrm{H}, J=5.1 \mathrm{~Hz}$ and $1.2 \mathrm{~Hz}, 5$ ' '-H), 7.62 (dd, $1 \mathrm{H}, J=3.0 \mathrm{~Hz}$ and $1.2 \mathrm{~Hz}, 3$ ' '-H), $7.76(\mathrm{dd}, 1 \mathrm{H}, J=2.7$ and $2.1 \mathrm{~Hz}, 5-\mathrm{H}), 7.86(2 \mathrm{H}, \mathrm{d}$, $J=9.0 \mathrm{~Hz} 3^{\prime}-\mathrm{H}$ and 5'-H), 7.92 (2H, d, J=9.0 Hz 2'-H and 6'-H), 8.38 (t, 1H, $\left.J=1.8 \mathrm{~Hz}, 2-\mathrm{H}\right)$. $\left.{ }^{13} \mathrm{C} \mathrm{NMR}\left(\mathrm{CDCl}_{3}\right) \delta 81.9,109.7,113.2,113.3,114.0,118.9,121.5\right), 124.7,125.7,126.6$, $128.7,129.1,133.5,133.6,136.7,141.9 . \lambda_{\max }($ Dioxane $) / \mathrm{nm} 403\left(\varepsilon / \mathrm{dm}^{3} \mathrm{~mol}^{-1} \mathrm{~cm}^{-1} 31,990\right)$. IR (Nujol): v 3570, 2246, 2210, 1653, 1610, 1538, 1506, 1329, 1296, 1266, 1249, 1209, 1075 , 978, 930, 841, $828 \mathrm{~cm}^{-1}$. MS (EI) $\mathrm{m} / z(\%)=326\left([\mathrm{M}]^{+}, 100\right), 301$ (27), 300 (32), 185 (10), 121 (22). HMRS: $m / z$ (EI) for $\mathrm{C}_{19} \mathrm{H}_{10} \mathrm{~N}_{4} \mathrm{~S}$; calcd 326.0626; found: 326.0626. Anal. Calcd for $\mathrm{C}_{19} \mathrm{H}_{10} \mathrm{~N}_{4} \mathrm{~S}$ : C, 69.92; H, 3.09; N, 17.17; S, 9.82. Found: C, 70.02; H, 3.39; N, 17.40; S, 10.05.

Synthesis of compound $\mathbf{4 c}$

A solution of aldehyde $4 \mathbf{a}(0.20 \mathrm{mmol}, 50 \mathrm{mg})$ and 1,3-diethyl-2-thiobarbituric acid (0.26 mmol, $52 \mathrm{mg})$ and triethylamine $(2$ drops $)$ in dichloromethane $(7 \mathrm{ml})$ was refluxed for 5 hours. The mixture was poured into water $(20 \mathrm{ml})$ and extracted with chloroform $(2 \times 50 \mathrm{ml})$. The organic layer was dried with anhydrous $\mathrm{MgSO}_{4}$ and evaporated under reduced pressure to give the crude product which by crystallization with petroleum ether gave the pure product $\mathbf{4 c}$.

1,3-Diethyl-dihydro-5-((1-(4-thiophen-2-yl)phenyl)-1H-pyrrol-2-yl)methylene)-2-

thioxopyrimidine-4,6(1H,5H)-dione 4c. Brown solid (33 mg, 39\%). Mp 230-232 ${ }^{\circ} \mathrm{C} .{ }^{1} \mathrm{H}$ NMR 
(Acetone- $\mathrm{d}_{6}$ ) $\delta$ 1.24-1.28 (m, 6H, 2xNCH $\left.\mathrm{CH}_{3}\right), 4.50-4.52\left(\mathrm{~m}, 4 \mathrm{H}, 2 \mathrm{xNCH}_{2} \mathrm{CH}_{3}\right), 6.76$ (dd, $1 \mathrm{H}, J=3.3$ and $2.7 \mathrm{~Hz}, 4-\mathrm{H}), 7.17\left(\mathrm{dd}, 1 \mathrm{H}, J=4.5\right.$ and $\left.3.6 \mathrm{~Hz},{ }^{\prime}{ }^{\prime}-\mathrm{H}\right), 7.58(\mathrm{~d}, 2 \mathrm{H}, J=8.7 \mathrm{~Hz}$, 3'-H and 5'-H), $7.60\left(\mathrm{dd}, 1 \mathrm{H}, J=5.1 \mathrm{~Hz}\right.$ and $\left.1.2 \mathrm{~Hz}, 5^{\prime}{ }^{\prime}-\mathrm{H}\right), 7.68(\mathrm{dd}, 1 \mathrm{H}, J=3,0$ and $1.2 \mathrm{~Hz}$, 3''-H), 7.85 ( tap $, 1 \mathrm{H}, J=1.8 \mathrm{~Hz}, 5-\mathrm{H}), 7.98$ (d, 2H, J=8.7 Hz, 2'-H and 6'-H), 8.32 (s, 1H, $\mathrm{C}=\mathrm{CH}), 8.80(\mathrm{dd}, 1 \mathrm{H}, J=3.3$ and $1.5 \mathrm{~Hz}, 3-\mathrm{H}) \cdot \lambda_{\max }($ Dioxane $) / \mathrm{nm} 433\left(\varepsilon / \mathrm{dm}^{3} \mathrm{~mol}^{-1} \mathrm{~cm}^{-1}\right.$ 45,790). IR $\left(\mathrm{CHCl}_{3}\right): v 1691,1657,1557,1282,1106,1044,824,784 \mathrm{~cm}^{-1}$. MS (ESI) $\mathrm{m} / z(\%)$ $=436\left([\mathrm{M}+\mathrm{H}]^{+}, 23\right)$. HMRS: $m / z$ (ESI) for $\mathrm{C}_{23} \mathrm{H}_{22} \mathrm{~N}_{3} \mathrm{O}_{2} \mathrm{~S}_{2}$; calcd 436.1148; found: 43.1132 . Anal. Calcd for $\mathrm{C}_{23} \mathrm{H}_{22} \mathrm{~N}_{3} \mathrm{O}_{2} \mathrm{~S}_{2}$ : C, 63.28; H, 5.08; N, 9.62; S, 14.69. Found: C, 63.47; H, 5.22; N, 9.85; S, 14.35.

\section{Synthesis of compound 5a}

To a solution of malononitrile $(0.24 \mathrm{mmol}, 0.016 \mathrm{~g})$ and aldehyde $3(0.19 \mathrm{mmol}, 0.50 \mathrm{mg})$ in ethanol $(10 \mathrm{ml})$ was added piperidine (1 drop). The solution was stirred at reflux during 3 hours. After cooled to room temperature the mixture was evaporated to dryness and the organic layer was extracted with chloroform $(2 \times 20 \mathrm{ml})$. and dried over anhydrous $\mathrm{MgSO}_{4}$. The product was purified through a silica gel column chromatography using mixtures of chloroform and light petroleum of increasing polarity. The fraction containing the purified product were collected and evaporated under vacuum. Recrystallization from light petroleum/ether gave the pure compound.

2-((5-(4-(1H-Pyrrol-1-yl)phenyl)thiophen-2-yl)methylene)malononitrile 5a. Yellow solid (25 mg, 43\%). Mp 221-223 ${ }^{\circ} \mathrm{C} .{ }^{1} \mathrm{H}$ NMR $\left(\mathrm{CDCl}_{3}\right) \delta$ 6.40-6.41 (m, 2H, 3''-H and 4' '-H), 7.15-7.17 (m, 2H, 2' '-H and 5' '-H), 7.45 (d, 1H, J=3.9 Hz, 4-H), 7.48 (d, 2H, J=9 Hz, 3'-H and 5'-H) , $7.80(\mathrm{~d}, 1 \mathrm{H}, J=3.9 \mathrm{~Hz}, 3-\mathrm{H}), 7.78\left(\mathrm{~d}, 2 \mathrm{H}, J=9 \mathrm{~Hz}, 2^{\prime}-\mathrm{H}\right.$ and $\left.6^{\prime}-\mathrm{H}\right), 7.81(\mathrm{~s}, 1 \mathrm{H}, \mathrm{C}=\mathrm{CH}) .{ }^{13} \mathrm{C}$ NMR $\left(\mathrm{CDCl}_{3}\right) \delta 111.4,113.3,114.1,118.9,120.5,124.4,127.9,129.2,134.2,140.0,141.9$, 150.5, 155.4. $\lambda_{\max }$ (Dioxane) $/ \mathrm{nm} 416\left(\varepsilon / \mathrm{dm}^{3} \mathrm{~mol}^{-1} \mathrm{~cm}^{-1} 39,180\right)$. IR $\left(\mathrm{CHCl}_{3}\right): v$ 3179, 3051, 2221, 1606, 1530, 1568, 1494, 1325, 1264, 1245, 1210, 1141, 1069, 945, 919, 832, 817, 807, $606 \mathrm{~cm}^{-1}$. Anal. Calcd. for $\mathrm{C}_{18} \mathrm{H}_{11} \mathrm{~N}_{3} \mathrm{~S}$ : Found: C, 71.58; H, 3.69; N, 13.72. \% CHNS requires: C, $71.74 ; \mathrm{H}, 3.68 ; \mathrm{N}, 13.94$.

Synthesis of compound $\mathbf{5 b}$

A solution of aldehyde $3(0.20 \mathrm{mmol}, 50 \mathrm{mg})$ and 1,3-diethyl-2-thiobarbituric acid $(0.26$ $\mathrm{mmol}, 52 \mathrm{mg})$ and triethylamine $(0.02 \mathrm{mmol})$ in dichloromethane $(5 \mathrm{ml})$ was refluxed for 4 hours. The mixture was poured into water $(20 \mathrm{ml})$ and extracted with chloroform $(2 \times 50 \mathrm{ml})$. 
The organic layer was dried with anhydrous $\mathrm{MgSO}_{4}$ and evaporated under reduced pressure to give the crude product which by crystallization with hexane we obtain the pure product $\mathbf{5 b}$.

5-((5-(4-(1H-Pyrrol-1-yl)phenyl)thiophen-2-yl)methylene)-1,3-diethyl-dihydro-2thioxopyrimidine-4,6(1H,5H)-dione 5b. Red solid (86 mg, 65\%). Mp 280-282 ${ }^{\circ} \mathrm{C} .{ }^{1} \mathrm{H}$ NMR $\left(\mathrm{CDCl}_{3}\right) \delta$ 1.26-1.39 (m, 6H, 2xNCH $\left.\mathrm{CH}_{3}\right), 4.57-4.64\left(\mathrm{~m}, 4 \mathrm{H}, 2 \mathrm{xNCH}_{2} \mathrm{CH}_{3}\right), 6.39-6.41(\mathrm{~m}$, 2H, 3' '-H and 4' '-H), 7.16-7.17 (m, 2H, 2' -H and 5' '-H), 7.47 (d, 2H, J=8,0 Hz, 3'-H and 5'-H), 7.56 (d, 1H, $J=4.0 \mathrm{~Hz}, 4-\mathrm{H}), 7.87$ (d, 2H, J=8,0 Hz, 2'-H and 6'-H), 7.89 (d, 1H, $J$ $=4.0 \mathrm{~Hz}, 3-\mathrm{H}) 8.67(\mathrm{~s}, 1 \mathrm{H}, \mathrm{C}=\mathrm{CH}) .{ }^{13} \mathrm{C} \mathrm{NMR}\left(\mathrm{CDCl}_{3}\right) \delta 12.4,12.5,43.2,43.9,110.3,111.3$, $118.9,120.4,124.6,128.1,130.2,136.7,141.7,157.3,149.6,159.9,160.2,161.0,178.7 . \lambda_{\max }$ (Dioxane)/nm $465\left(\varepsilon / \mathrm{dm}^{3} \mathrm{~mol}^{-1} \mathrm{~cm}^{-1} 45,790\right)$. IR (Nujol): 2350, 1684, 1662, 1606, 1548, $1491,1413,1334,1267,1247,1105,1077,787 \mathrm{~cm}^{-1}$. MS (ESI) $\mathrm{m} / z(\%)=436\left([\mathrm{M}+\mathrm{H}]^{+}, 20\right)$, 387 (11), 386 (39), 382 (20), 381 (70), 360 (29), 359 (84), 354 (14), 353 (44), 342 (37), 341 (100), 331 (14), 314 (14), 285 (12), 268 (27), 267 (89), 240 (14) and 239 (35). HMRS: $m / z$ (ESI) for $\mathrm{C}_{23} \mathrm{H}_{22} \mathrm{~N}_{3} \mathrm{O}_{2} \mathrm{~S}_{2}$; calcd 436.1148; found: 43.1155. Anal. Calcd for $\mathrm{C}_{23} \mathrm{H}_{22} \mathrm{~N}_{3} \mathrm{O}_{2} \mathrm{~S}_{2}$ : C, 63.28; H, 5.08; N, 9.62; S, 14.69. Found: C, 63.10; H, 5.30; N, 9.87; S, 14.91.

\subsection{Instruments}

NMR spectra were obtained on a Varian Unity Plus Spectrometer at an operating frequency of $300 \mathrm{MHz}$ for ${ }^{1} \mathrm{H}$ NMR and $75.4 \mathrm{MHz}$ for ${ }^{13} \mathrm{C}$ NMR or a Bruker Avance III 400 at an operating frequency of $400 \mathrm{MHz}$ for ${ }^{1} \mathrm{H}$ NMR and $100.6 \mathrm{MHz}$ for ${ }^{13} \mathrm{C}$ NMR using the solvent peak as internal reference at $25^{\circ} \mathrm{C}$. All chemical shifts are given in ppm using $\delta_{\mathrm{H}} \mathrm{Me}_{4} \mathrm{Si}=0$ ppm as reference and $J$ values are given in Hz. Assignments were made by comparison of chemical shifts, peak multiplicities and $J$ values and were supported by spin decouplingdouble resonance and bidimensional heteronuclear HMBC and HMQC correlation techniques. IR spectra were determined on a BOMEM MB 104 spectrophotometer using KBr discs. UVvisible absorption spectra $(200-800 \mathrm{~nm})$ were obtained using a Shimadzu UV/2501PC spectrophotometer. Mass spectrometry analyses were performed at the "C.A.C.T.I. -Unidad de Espectrometria de Masas" at the University of Vigo, Spain. Thermogravimetric analysis of samples was carried out using a TGA instrument model Q500 from TA Instruments, under high purity nitrogen supplied at a constant $50 \mathrm{~mL} \mathrm{~min}^{-1}$ flow rate. All samples were subjected to a $20{ }^{\circ} \mathrm{C} \min ^{-1}$ heating rate and were characterized between 25 and $500{ }^{\circ} \mathrm{C}$. All melting points were measured on a Gallenkamp melting point apparatus and are uncorrected. Cyclic 
voltammetry (CV) was performed using a potentiostat/galvanostat (AUTOLAB /PSTAT 12) with the low current module ECD from ECO-CHEMIE and the data analysis processed by the General Purpose Electrochemical System software package also from ECO-CHEMIE. Three electrode-two compartment cells equipped with vitreous carbon-disc working electrodes, a platinum-wire secondary electrode and a silver-wire pseudo-reference electrode were employed for cyclic voltammetric measurements. The concentration of the compounds were 1 mmol dm${ }^{-3}$ and $0.1 \mathrm{~mol} \mathrm{dm}^{-3}\left[\mathrm{NBu}_{4}\right]\left[\mathrm{BF}_{4}\right]$ was used as the supporting electrolyte in dry $N, N$ dimethylformamide solvent. The cyclic voltammetry was conducted usually at $0.1 \mathrm{Vs}^{-1}$, or at different scan rates $\left(0.02-0.50 \mathrm{Vs}^{-1}\right)$, for investigation of scan rate influence. The potential is measured with respect to ferrocenium/ferrocene as an internal standard.

\subsection{Solvatochromic study}

The solvatochromic study was performed using $10^{-4}$ mol dm ${ }^{-3}$ solutions of compounds $\mathbf{2 - 5}$ in several solvents at room temperature using a Shimadzu UV/2501PC spectrophotometer.

\subsection{Nonlinear optical measurements using the hyper-Rayleigh scattering (HRS) method} Hyper-Rayleigh scattering (HRS) was used to measure the first hyperpolarizability $\beta$ of response of the molecules studied. The experimental set-up for hyper-Rayleigh measurements employed a q-switched Nd:YAG laser and is similar to the one presented by Clays et al. ${ }^{16}$ Details of the experimental procedure used have been previously published. ${ }^{10} \mathrm{We}$ emphasize that particular care was taken to avoid reporting artificially high first hyperpolarizabilities by using a pair of interference filters to estimate and correct for the presence of a possible contamination of the hyper Rayleigh signal by molecular fluorescence near $532 \mathrm{~nm}$. Further cautions include normalizing the hyper-Rayleigh signal at each pulse using the second harmonic signal from a $1 \mathrm{~mm}$ quartz plate to compensate for fluctuations in the temporal profile of the laser pulses due to longitudinal mode beating and the filtering of the solutions, using a $0.2 \mu \mathrm{m}$ porosity filter, to avoid spurious signals from suspended impurities.

Dioxane was used as a solvent for all measurements. The small hyper-Rayleigh signal that arises from dioxane was taken into account according to the expression

$$
I_{2 \omega}=G\left(N_{\text {solvent }}\left\langle\beta_{\text {solvent }}^{2}\right\rangle+N_{\text {solute }}\left\langle\beta_{\text {solute }}^{2}\right\rangle\right) I_{\omega}^{2}
$$

where the factor $\mathrm{G}$ is an instrumental factor that takes into account the detection efficiency (including geometrical factors and linear absorption or scattering of the second harmonic light on its way to the detector) and local field corrections. The concentrations of the solutions 
under study were chosen so that the corresponding hyper-Rayleigh signals fell well within the dynamic range of detection system. We have assumed that molecules could be treated as linear donor-acceptor chromophores with a first hyperpolarizability tensor dominated by a single longitudinal element, $\beta_{333}=\beta$, associated with the charge transfer axis. In this case the measured HyperRayleigh signal is related to the value of the dominant tensor element through the relation $\beta=\sqrt{\left\langle\beta_{H R S}^{2}\right\rangle}=\sqrt{\left\langle\beta_{Z Z Z}^{2}\right\rangle+\left\langle\beta_{X Z Z}^{2}\right\rangle}$ were the angle brackets denote an average for the random molecular orientations in the solution. Here we have adopted a laboratory reference frame in which the incident fundamental light propagates along the $\mathrm{X}$ axis and was vertically polarized along the $\mathrm{Z}$ direction, while no polarization discrimination was carried out in the detection arm which is orientated along the laboratory frame $\mathrm{Y}$ axis. To calibrate our system a reference solution of $p$-nitroaniline ( $p \mathrm{NA}$ ) dissolved in dioxane at a concentration of $1 \times 10^{-2} \mathrm{~mol} \mathrm{dm}^{-3}$ (external reference method). Kaatz and Shelton ${ }^{20 \mathrm{a}}$ have measured the value of $\beta_{333}$ of $p \mathrm{NA}$ in dioxane at $1064 \mathrm{~nm}$ to be $40 \times 10^{-30}$ esu using the so-called Taylor convention for the first hyperpolarizability. ${ }^{20 \mathrm{~b}}$ This value includes a correction factor of 1.88 that accounts for the most recent measurement of the $\mathrm{CCl}_{4}$ hyper-Rayleigh scattering signal which was used as a reference. ${ }^{21}$

\section{Acknowledgments}

The author wish to thank the Fundação para a Ciência e Tecnologia (Portugal) and FEDERCOMPETE for financial support through the Centro de Química and Centro de Física Universidade do Minho, Projects PTDC/QUI/66251/2006 (FCOMP-01-0124-FEDER007429), PTDC/CTM/105597/2008 (FCOMP-01-0124-FEDER-009457), PEstC/QUI/UI0686/2011 (F-COMP-01-0124-FEDER-022716) and a PhD grant to M. C. R. Castro (SFRH/BD/78037/2011). The NMR spectrometer Bruker Avance III 400 is part of the National NMR Network and was purchased within the framework of the National Program for Scientific Re-equipment, contract REDE/1517/RMN/2005 with funds from POCI 2010 (FEDER) and FCT.

\section{References and notes}

1 (a) Kanis, D. R.; Ratner, M. A.; Marks, T. J. Chem. Rev. 1994, 94, 195. (b) Verbiest, T.; Houbrechts, S.; Kauranen, M.; Clays, K.; Persoons, A. J. Mater. Chem. 1997, 7, 2175. (c) Cho, M. J.; Choia, D. H.; Sullivan, P. A.; Akelaitis, A. J. P.; Dalton, L. R. Prog. Polymer Sci. 2008, 33, 1013. (d) Benight, S. J.; Bale, D. H.; Olbricht, B. C.; Dalton, L. R. J. Mater. 
Chem. 2009, 19, 7466. (e) Dalton, L. R.; Sullivan, P. A.; Bale, D.; Olbricht, B.; Davies, J.; Benight, S.; Kosilkin, I.; Robinson, B. H.; Eichinger, B. E.; Jen, A. K.-Y. In Organic Thin Films for Photonic Applications, "Organic Electro-Optic Materials Understanding Structure/Function Relationships Critical to the Optimization of Electro-Optic Activity", Herman, W., et al Eds.; ACS Symposium Series: American Chemical Society: Washington, DC, 2010, Vol. 1039, chap. 2, pp 13-33. (f) Dalton, L. R.; Sullivan, P. A.; Bale, D. H. Chem. Rev. 2010, 110, 25 and references cited.

2 For some examples see: (a) Dirk, C. W.; Katz, H. E; Schilling, M. L; King, L. A. Chem. Mat. 1990, 2, 700. (b) Rao, V. P.; Jen, A. K.-Y.; Wong, K. Y.; Drost, K. J. Tetrahedron Lett. 1993, 34, 1747. (c) Jen, A. K.-Y.; Rao, V. P.; Wong, K. Y.; Drost, K. J. J. Chem. Soc., Chem. Commun. 1993, 90. (d) Rao, V. P.; Jen, Wong, K. Y.; Drost, K. J. J. Chem. Soc., Chem. Commun. 1993, 1118. (e) Miller, R. D.; Lee, V. Y.; Moylan, C. R. Chem. Mater. 1994, 6, 1023. (f) Chou, S.-S. P.; Sun, D.-J.; Lin, H.-C.; Yang, P.-K. Tetrahedron Lett. 1996, 37, 7279. (g) Shu, C.-F.; Tsai, W.-J.; Chen, J.-Y; Jen, A. K.-Y.; Zhang, Y.; Chen, T.-A. J. Chem. Soc., Chem. Commun. 1996, 2279. (h) Shu, C.-F.; Wang, Y.-K. J. Mat. Chem. 1998, 8, 833. (i) Hrobárik, P.; Sigmundová, I.; Zahradník, P. Synthesis 2005, 600. (j) Zajac, M.; Hrobarik, P.; Magdolen, P. Foltínová, P.; Zahradník, P. Tetrahedron, 2008, 64, 10605. (k) Kulhanek, J.; Burés, F. Beils. J. Org. Chem. 2012, 8, 25 and references cited.

3 (a) Varanasi, P. R.; Jen, A. K.-Y.; Chandrasekhar, J.; Namboothiri, I. N. N.; Rathna, A. J. Am. Chem. Soc. 1996, 118, 12443. (b) Albert, I. D. L.; Marks, T. J.; Ratner, M. A. J. Am. Chem. Soc. 1997, 119, 6575. (c) Breitung, E. M.; Shu, C.-F.; McMahon, R. J. J. Am. Chem. Soc. 2000, 122, 1154. (d) Ra, C. S.; Kim, S. C.; Park, G. J. Mol. Struct. (Theochem) 2004, 677, 173. (e) Hrobarik, P.; Zahradnik, P.; Fabian, W. M. F. Phys. Chem. Chem. Phys. 2004, 6, 495. (f) Benková, Z.; Cernusák, I.; Zahradnik, P. Struct. Chem. 2006, 17, 287. (g) Benková, Z.; Cernusák, I.; Zahradník, P. Mol. Phys. 2006, 104, 2011.

4 (a) Morley, J. O. J. Chem. Soc. Faraday Trans. 1991, 87, 3009. (b) Bradamante, S.; Facchetti, A.; Pagani, G. A. J. Phys. Org. Chem. 1997, 10, 514. (c) Groenendaal, L.; Bruining, M. J.; Hendrickx, E. H. J.; Persoons, A.; Vekemans, J. A. J. M.; Havinga, E. E.; Meijer E. W. Chem. Mater. 1998, 10, 226. (d) Facchetti, A.; Abbotto, A.; Beverina, L.; van der Boom, M. E.; Dutta, P.; Evmenenko, G.; Marks, T. J.; Pagani, G. A. Chem. Mat. 2002, 14, 4996. (e) Facchetti, A.; Abbotto, A.; Beverina, L.; van der Boom, M. E.; Dutta, P.; Evmenenko, G.; Pagani, G. A. Marks, T. J. Chem. Mat. 2003, 15, 1064. (f) Audebert, 
P.; Kamada, K.; Matsunaga, K.; Ohta, K. Chem. Phys. Lett. 2003, 367, 62. (g) Abbotto, A.; Beverina, L.; Bradamante, S.; Facchetti, A.; Klein, C.; Pagani, G. A.; Redi-Abshiro, M.; Wortmann, R. Chem. Eur. J. 2003, 9, 1991. (h) Abbotto, A.; Beverina, L.; Bradamante, S.; Facchetti, A.; Pagani, G. A.; Bozio, R.; Ferrante, C.; Pedron, D.; Signorini, R. Synthetic Met., 2003, 14, 4996.

5 (a) Raposo, M. M. M.; Sousa, A. M. R. C.; Fonseca, A. M. C.; Kirsch, G. Tetrahedron 2005, 61, 8249. (b) Raposo, M. M. M.; Sousa, A. M. R. C.; Kirsch, G.; Ferreira, F.; Belsley, M.; Matos Gomes, E.; Fonseca, A. M. C. Tetrahedron 2005, 61, 11991. (c) Raposo, M. M. M.; Sousa, A. M. R. C.; Kirsch, G.; Cardoso, P.; Belsley, M.; Matos Gomes, E.; Fonseca, A. M. C. Org. Lett. 2006, 8, 3681.

6 (a) Davies, J. A.; Elangovan, A.; Sullivan, P. A.; Olbricht B. C.; Bale, D. H.; Ewy, T. R.; Isborn, C. M.; Eichinger, B. E.; Robinson, B. H.; Reid, P. J.; Li, X.; Dalton, L. R. J. Am. Chem. Soc. 2008, 130, 10565. (b) Li, Q.; Lu, C.; Zhu, J.; Fu, E.; Zhong, C.; Li, S.; Cui, Y.; Qin, J.; Li, Z. J. Phys. Chem. B 2008, 112, 4545. (c) Abbotto, A.; Beverina, L.; Manfredi, N.; Pagani, G. A.; Archetti, G.; Kuball, H. G.; Wittenburg, C.; Heck, J.; Holtmann, J. Chem. Eur. J., 2009, 15, 6175. (d) Ma, X.; Liang, R.; Yang, F.; Zhao, Z.; Zhang, A.; Song, N.; Zhou, Q.; Zhang, J. J. Mater. Chem. 2008, 18, 1756 (e) Ma, X.; Ma, F.; Zhao, Z.; Song, N.; Zhang, J. J. Mater. Chem. 2009, 19, 2975. (f) Ma, X.; Ma, F.; Zhao, Z.; Song, N.; Zhang, J. J. Mater. Chem. 2010, 20, 2369.

7 (a) Batista, R. M. F.; Costa, S. P. G.; Malheiro, E. L.; Belsley, M.; Raposo, M. M. M. Tetrahedron 2007, 63, 4258. (b) Batista, R. M. F.; Costa, S. P. G.; Belsley, M.; Raposo, M. M. M. Tetrahedron 2007, 63, 9842. (c) Pina, J.; Seixas de Melo, S.; Batista, R. M. F.; Costa, S. P. G.; Raposo, M. M. M. Phys. Chem. Chem. Phys. 2010, 12, 9719. (d) Raposo, M. M. M.; Fonseca, A. M. C.; Castro, M. C. R.; Belsley, M.; Cardoso, M. F. S.; Carvalho, L. M.; Coelho, P. J. Dyes Pigments 2011, 91, 62. (e) Raposo, M. M. M.; Castro, Schellenberg, P.; M. C. R.; Fonseca, A. M. C.; Belsley, M. Tetrahedron 2011, 67, 5189.

8 (a) Raposo, M. M. M.; Sousa, A. M. R. C.; Fonseca, A. M. C.; Kirsch, G. Tetrahedron 2006, 62, 3493. (b) Raposo, M. M. M. in Targets in Heterocyclic Systems: Chemistry and Properties, "Recent developments in the chemistry of 2-thienylpyrroles: synthesis, reactivity and applications", Attanasi, O. A.; Spinelli, D. Eds.; Royal Society of Chemistry: London, 2008, Vol. 11, pp 122-154.

9 Delen, Z.; Lahti, P. M. J. Org. Chem. 2006, 71, 9341.

10 Herbivo, C.; Comel, A.; Kirsch, G.; Fonseca, A. M. C.; Belsley, M.; Raposo, M. M. M. Dyes and Pigments 2010, 86, 217. 
11 Oliva, M. M.; Casado, J.; Raposo, M. M. M.; Fonseca, A. M. C.; Hartmann, H.; Hernández, V.; Navarrete, J. T. L. J. Org. Chem. 2006, 71, 7509.

12 Fitzner, R.; Reinold, E.; Mishra, A.; Mena-Osteritz, E.; Ziehlke, H.; Körner, C.; Leo, K.; Riede, M.; Weil, M.; Tsaryova, O.; Weib, A.; Uhrich, C.; Pfeiffer, M.; Bauerle, P. Adv. Funct. Mater. 2011, 21, 897.

13 Zhou, E.; Wei, Q.; Yamakawa, S.; Zhang, Y.; Tajima, K.; Yang, C.; Hashimoto, K. Macromolecules 2010, 43, 821.

14 Pommerehne, J.; Vestweber, H.; Guss, W.; Mahrt, R. F.; Bässler, H.; Porsch, M.; Daub, J. Adv. Mater. 1995, 551.

15 Kamlet, M. J.; Abboud, J-L. M.; Abraham, M. H.; Taft, R. W. J. Org. Chem. 1983, 48, 2877. (b) Kamlet, M. J.; Abboud, J-L. M.; Abraham, M. H.; Taft, R. W. J. Am. Chem. Soc. 1977, 99, 6027.

16 (a) Clays, K.; Persoons, A. Rev. Sci. Instrum. 1992, 63, 3285. (b) Clays, K.; Persoons, A. Phys. Rev. Lett. 1991, 66, 2980.

17 (a) Kaatz, P.; Shelton, D. P. J. Chem. Phys. 1996, 105, 3918; (b) Reis, H. J. Chem. Phys. 2006, 125, ARTN 014506.

18 (a) Oudar, J. L. J. Chem. Phys. 1977, 67, 446; (b) Oudar, J. L.; Chemla, D. S. J. Chem. Phys. 1977, 66, 2664; (c) Zyss, J.; Oudar, J. L. Phys. Rev. A 1982, 26, 2016.

19 Costa, S. P. G.; Batista, R. M. F.; Cardoso, P.; Belsey, M.; Raposo, M. M. M. Eur. J. Org. Chem. 2006, 17, 3938.

20 (a) Kaatz, P.; Shelton, D. P. J. Chem. Phys. 1996, 105, 3918; (b) Reis, H. J. Chem. Phys. 2006, 125, ARTN 014506.

21 Pyatt, R. D.; Shelton, D. P. J. Chem. Phys. 2001, 114, 9938. 